\title{
E-governance in revenue collection and administration
}

\author{
T. M. Nisar \\ School of Management, University of Southampton, UK
}

\begin{abstract}
E-government is about the use of information communication technologies (ICTs) to offer better public service at a lower cost. However, there is a trade-off to be made between implementing e-government with ICTs and the public ability to reach and access electronic information. Access to all official information and service offerings of a public agency is generally of e-government's primary focus. This paper presents the findings of a research into the issues regarding the role of e-governance in tax administration especially incorporating ICTs technologies. Recent trends in public taxation stress the need of developing a system of tax assessment and collection that involves internet services. Using a case study of the UK government department of HM Revenue and Customs, the paper examines the use of internet service for self-assessment, payment by internet and Pay As You Earn service for employers. The findings suggest that substantial progress has been made over recent years in developing an effective system of e-taxation by the UK government. The paper also identifies further requirements of the use of ICTs in e-taxation and potentials for future direction and initiatives.
\end{abstract}

Keywords: e-government, ICTs, revenue administration, automation, partnerships.

\section{Introduction}

Common goals associated with the practice of e-government are often defined in terms of the use of information and communication technologies (ICTs) and how they can potentially improve public service operations. The fact that ICTs now account for rapid improvements in general service delivery, within the context of public sector performance, they are also increasingly being seen as a panacea to a 
plethora of problems that governments face in serving their constituencies effectively. This is especially so in revenue and tax collection, where the public agencies frequently encounter the problems of trust and partnerships, without which it would be difficult to improve collaborative operations and service delivery to the citizens. In such cases, e-government has been touted as a means to save costs while at the same time improving quality, timeliness, and access to services. More broadly, policy makers have noted its role in improving the efficiency and effectiveness of public administration [4, 5], including its role in increasing transparency in administration, reduce corruption, and increase political participation [4].

Despite the increased interest in the role of ICTs, extant research has variously noted that e-government projects often fail either totally or partially, especially in the later phases of their development [2]. While various theories have been advanced to help understand these failures [2], there are few empirical studies that focus on the design and implementation of projects in areas such as revenue collection and administration. This paper examines one such case, where the e-government project has been particularly successful in realizing key efficiency goals, although potential improvements will need to be made in the way various services are integrated and the levels of coordination achieved. Our focus here is on the e-government services, which include online tax returns, both individual and corporate, all of which are important to citizens wishing access to relevant government programmes. While the study's primary goal is to delineate the extent to which automation has been achieved in service delivery, it also investigates the systemic and institutional factors responsible for shaping and influencing the e-governance processes.

The remainder of the paper is organised as follows: first, we describe the overall project briefly and how it forged institutional partnerships with the various relevant government and private agencies for the delivery of services; then we discuss the results including an analysis of the various challenges faced by the programme; and finally we analyse the critical success factors and provide concluding remarks indicating the potential areas of improvement.

\section{E-taxation in the UK}

The UK Government provides through its department of HM Revenue and Customs (HMRC) advanced ICT-enabled tax services to customers. HMRC has since 1999 been in the process of introducing fully automated systems to gain efficiency savings. A key objective was to create a fully automated tax portfolio that would reduce the amount of manual time required to improve efficiency, as well as streamlining the system for both the employer and employee customers. Through the automated system, tax repayments can now be made within 48 hours. Incentives are provided to customers to use the online service; for example, companies with fewer than 50 employees are offered $£ 250$ if they file their PAYE returns online. However, all businesses with more than 250 employees were mandated to file their PAYE returns online. Take-up of the 
e-channel for income tax self assessments has risen from $12 \%$ in $2003 / 04$ to $25 \%$ in the 2005/06 tax year but it is still moderate compared to other countries.

Key Performance Indicators (KPIs) are defined and tracked and are used to improve the service provided. Turnaround times are measured and the number of enquiries is used as a measure of how efficient the self help service is. To ensure quality, systematic checking takes place that flag cases for attention if assigned parameters are breached, such as the time to respond falling outside allowed limits, or the tax as a percentage of income falling outside expected limits. The Department claims that case handling is fully automated from receiving the customer report to paying tax refunds electronically.

At this juncture, it is difficult to make a quantitative assessment of the cost savings but anecdotal evidence suggests that the HMRC have begun to reap the benefits in the form of moderate productivity improvements. Additionally, sophistication of the customer interface is also high. In the light of these developments, the Department expects that further automation and increased take-up of the online services will enable it to achieve a net staff reduction of 12,500 by 2008 .

\subsection{Organisational context}

In the UK, the revenue service is delivered through a centralised organisation. The core of the revenue service's operations, form and payment processing, is particularly amenable to automation. In combination, these factors provide a highly favourable environment for ICTs to transform the heart of the service, making the revenue the most highly ICT-enabled service within the government.

\subsubsection{Self assessment}

The first Self Assessment (SA) tax return was issued in April 1997. Under SA online the website provides information about what citizens have to do to get their tax right first time, when they have to do it, and what happens if they do not meet the deadlines. One of the biggest changes is that tax payers' bill will be based on the figures that they provide on their tax return without the Revenue first checking them in detail and agreeing them. A range of SA internet filing enabled software products are now available, which allows the following facilities: for individuals, trusts, partnerships and agents to file SA tax returns over the internet, view statements, view their records of account, receive notifications and reminders by email or text messaging and make payments. Agents have the option to use the ELS to file their clients' forms and returns. In addition to SA, the Revenue also deals with a number of other tax related services, including:

Internet service for PAYE: the service enables employers to send and receive PAYE forms and returns online, and view statutory notices and reminders. Agents or payroll bureaux that administer PAYE on behalf of employers can use PAYE Online for Agents. The online filing options include various PAYE Internet filing enabled software products. Similarly, the Revenue also provides a range of Electronic Data Interchange (EDI) enabled software products. 
Corporation Tax (CT) Online: the service allows for companies and agents to file CT returns over the internet, and view up-to-date position on liabilities and payments.

Table 1: $\quad$ An example of Inland Revenue's e-services - July 2001 intake.

Internet service for Self Assessment

Total number of taxpayers registered 161,511

to use the service

Total number of 199-2000 tax returns

received over the internet

Total number of 2000-2001 tax returns (due date 31/01/02) received over the Internet between 06/04/01 and 31/07/01

Payment by Internet (Billpay) -SA

Total number of SA payments received over the Internet between $10 / 01$ and $11 / 07 / 01$

Total value of those payments

Internet service for PAYE

Total number of Employer registrations between 21/02/01 and 31/07/01

Total number of Agent registrations between 19/02/01 \& 31/07/01

Total number of 2000-01 End of Year returns (due date 19/05/01) received over the Internet from both employers and agents between 09/04/01 and 31/07/01

Total number of 2000-01 P11D packages received over the Internet from both employers and agents between 04/06/01 \& 31/07/01

Total number of 2001-02 P46's received over the Internet from both employers and agents between 04/06/01 and 31/07/01

Payments by Internet (Billpay) PAYE

Total number of PAYE payments received over the Internet between 09/04/01 and 11/07/01

Total value of those payments
39,290

14,822

1,900

$£ 2,390,889$

5991

253

2,673

126

29

165

$£ 175,980$ 


\subsubsection{Returnees' costs of e-taxation}

If returnees are using the free Inland Revenue online software, then the only cost to them is any phone charges incurred whilst online and any charges that their Internet Service Provider (ISP) makes for using their service. This depends on returnees' own ISP and the contract they have with them. Returnees can also use a range of Internet filing enabled 3rd party software products that have successfully passed the Revenue's testing procedures.

\subsubsection{Security and reliability}

Revenue officials suggest that filing tax return online is secure, accurate and returnees get immediate acknowledgement of receipt, plus receiving a significantly faster repayment if they are owed money. The HMRC has taken measures to ensure the online services are secure. The Department also constantly monitors the services for any potential security breaches. Security measures that the department has implemented are:

\subsubsection{Authentication}

Access is only available by user ID/Password (or digital certificate). The Government Gateway uses the postal address registered on the HMRC systems to send returnees confirmation of their User IDs and service Activation PINs. Enrolment expires if returnees do not activate their chosen service within 28 days.

\subsection{EDI service}

EDI (Electronic Data Interchange) is the transfer of data from an application running on the computer of one organisation to an application running on the computer of another organisation, with no manual intervention. Employers who already have EDI capability, or EDI compatible payroll software, are likely to find it cost effective.

Any organisation that handles high volumes of employers' PAYE forms and returns, e.g. employers with a large number of staff, typically 1000's would find the use of EDI cost effective. Similarly, it is useful for employers with a high staff turnover, e.g. those who employ a lot of temporary or casual staff. In general, the benefits of using EDI include the following:

Savings: whilst there may be initial setting up costs, longer term savings are likely to be achieved in areas such as paper, printing, postage, paper storage and administration. Increased efficiency and improved customer service are also recognised as benefits of using EDI.

Flexibility: the EDI service is flexible. This enables employers to implement EDI only for the forms and returns that will benefit their payroll office. EDI allows the employer to send data to the Inland Revenue at a time that suits them. There is no restriction on the time when data can be sent. 
Quality and Accuracy: EDI is designed to improve the quality of service, since it enables information to go from one computer application to another with no manual intervention. This reduces the likelihood of errors that could have been incurred as a result of re-keying data from paper forms. The Department has figured that $2 \%$ of all forms that are hand written have errors introduced when re-keyed. This finding is based on an experienced key operator carrying out the action. By using EDI the forms are processed with 100\% accuracy.

\section{Improving corporate services}

The corporate services that underpin frontline service delivery, such as ICT, finance, human resources and procurement services, are a vital part of making public services work. One of the critical features of frontline service delivery is the way partnerships are forged and developed between different operational entities. It is a fact that sharing corporate services between several organisations promises to deliver economies of scale and better utilisation of the resources available. On the other hand, increased purchasing power is promised by better coordination of procurement of goods and services between public sector bodies.

Typical partnership projects are about working together to develop new shared services - for example the recent integration of revenue tax and social security service. This partnership has developed a browser-based system for sharing and retrieving tax data. It enables better tackling of tax assessment information, by joining up previously disjointed information, showing patterns and correlations.

\subsection{The design and effects of partnership programmes}

Since 1997 when the e-Services Programme began, the Revenue has changed significantly. Whilst the many projects undertaken by the Revenue delivered many benefits in their own right, the programme as a whole has challenged both the Department's bureaucracy and tax advisory/accountancy service providers to think strategically about working together and change their attitudes towards what can be achieved. The Department has taken a number of institutional measures to meet these challenges, some of which are briefly described below.

\subsubsection{A better technology infrastructure in place}

Most tangibly there is now in place a whole set of technical infrastructure and offerings that were not there before. These include portals and other systems offering services direct to the citizen (including private agents), joined up databases (e.g. EDI) to enable both public and private service providers to plan together to deliver more effective and efficient services, and networks and software that provide the mechanism for all sorts of future information sharing.

\subsubsection{Better relations between many institutions}

Many agents previously only had sporadic or silo-based experience of working together. The e-Services Programme has encouraged authorities (both government and private) to get to know each other much better across the full 
range of services and at a new level of both strategic and operational detail. As such it has catalysed a step change in the relationship between key strategic officers in the Revenue, such as heads of IT, information management officers and customer services managers. This has to an extent filtered through to the other parts of their organisations. The result is that many functionaries are now far more likely to think of working with each other than previously, and not just in relation to e-government. Various department sections and private agents such as tax advisers also know how to work together far more than they did before the programme. Partnerships that chose to focus on the skills building opportunities of working together undertook a wide range of activities:

- organising and facilitating specialist interest groups (e.g. agents), offering participants the chance to share common problems and solutions in their professional areas;

- exploring the use of case automation to help increase confidence in the system; and

- developing shared methodologies for tackling particular tasks, such as introducing case related good practice, or implementing particular technical solutions.

\section{Discussion}

In the latest stage of its drive to realise maximum automation, the e-services project has enhanced off-the-shelf software to enable the electronic delivery of key documents, including data interchange plans, key information sources and work-out manuals. It also has enabled publication of these documents on the Internet in an easily searchable form. Making this kind of taxation information easier to locate and to understand helps to increase citizen engagement in the revenue collection process, thus improving the quality of the overall taxation system.

In line with the above example, the study finds that comprehensive, well designed and customer focused websites are available, providing tax returnees with detailed information on the tax system and the service procedures that apply for individuals and businesses. As a result, a number of different types of transactions, such as filing income tax returns, and making electronic payments, can be completed online (see Table 1). The Revenue has also demonstrated the ability to analyse user data to generate customer insights in order to refine service strategy. The implementation of EDI is one such example of improved service resulting directly from data analysis and customer feedback.

In general, the level of automation possible is dependent on the nature of the service. Services which are centrally delivered and are highly 'bitable' lend themselves naturally to a higher degree of automation (for example, the clerical/transactional processing of tax returns, lends itself more fully than the process of delivering healthcare to patients). Other areas may include the extent 
of automation in relation to the manual effort required for end-to-end processing and quality checking within departments. The present study finds that highly bitable services like self-assessment have reached higher degrees of automation. The automated SA case handling micro theme covers the processing of customer information using ICTs from initial customer contact through to completed transaction.

The main objective of automation is to improve efficiency by saving time and cost. Savings from automation result from greater productivity of staff and reduced paper case handling requirements leading to savings in mail carrier services, registry, space consumption and office supplies. Online applications directly feed into the workflow system which helps to reduce lead times. In addition, decreasing error rates leads to lower cost of quality checking. The study finds that sophistication of automated case handling is high. For example, OCR (Optical Character Recognition) scanning has been used by the Revenue to speed the process of digitising paper based returns. This has mainly translated into increased levels of take-up to enable substantial cost or time savings. Other successful innovations include:

- standard cases (that is, cases with no exceptional attributes) are handled electronically end-to-end, with minimal manual interventions;

- quality checking: cases scanned and assessed automatically, problem cases flagged automatically for attention; and

- process optimisation is driven by KPI results.

The study also finds that error and fraud detections have been significantly improved by automation. Real-time basic validation of returns is common, ensuring basic errors are corrected before they reach the back office processing systems. However, there is not much evidence of a department-wide integrated system offering a single customer view, despite many policy pronouncements on the contrary as noted above. The integration process has largely been treated as bolt-on changes rather than an inherent part of system design. The back office of the Department comprises a set of legacy systems integrated through middleware. Though some of these links are real-time, many are batch imposing a bottleneck on the whole system. By contrast, Australian Tax Office (ATO), for example, has been able to create a 'single customer view' of a taxpayer's accounts and a history of their interactions with the revenue/tax service. It is important to note that integration of databases and applications will be a key enabler of automated case handling. In this respect, many partner agents do make use of those systems in their business processes which provide integrated functionality such as assessment criteria but institutional-level partnerships still need to be strengthened to develop a single customer view.

Convincing professional sector users such as tax professionals and accountants to use the online channel has experienced mixed success. For example, many accountants wrongly perceived that they would be subjected to 
increased auditing pressure by using the online channel - which posed a barrier to use. In fact, the method of filing is totally independent from the assessment process. Legislative and institutional barriers around data sharing, in some cases perceived and in others real, are slowing progress towards integration of tax services with other government departments (and private agents). These hinder the transfer of information between departments (as well as between departments and private agents) and reduce the scope of service transformation and improvement initiatives. For instance, despite the fact that Revenue and Excise and Customs operate within the same ministerial department, there is not much evidence of ICT-based integration of both services. However, as noted above, the Revenue has taken a number of measures to increase the collaboration and partnerships among various taxation-related parties.

\section{Conclusion}

Though considerable attention has been focused on how e-government can help public agencies improve their services, there are relatively few studies that focus on the impacts of these services on the government agencies or the citizens themselves, especially in the context of tax and revenue collection [1-3]. HMRC has introduced fully automated processes to improve service provision and to gain efficiency savings. Case handling, a key plank of the revenue service, is now fully automated from receiving the customer report to paying tax refunds electronically. Fully automated end-to-end processes are also being gradually introduced in the case of general tax services. These measures have meant that take-up of the e-services for income tax self assessments are moderate but rising fast: it is forecast to rise from $12 \%$ in $2003 / 04$ to $25 \%$ in the $2005 / 6$ tax year. Through the automated system, tax repayments can be made within 48 hours.

Despite all the success in introducing automation, the Revenue can still adopt a number of measures for encouraging the delivery of efficient e-services. This is especially important as key e-access mediums are expected to be achieving growing levels of use up to 2005/6, whilst reflecting citizens concerns for a flexible approach to access medium development. In this respect, the Revenue will need to identify how their internal organisation and practices are being adapted to help deliver the changes necessary for e-government. In particular, all relevant department sections will need to demonstrate leadership of the e-agenda and integration management capacity. This would involve the following measures:

- identifying key operational sections and their respective roles, responsibilities and activities in the integration process; and

- identifying engagement with professional services such as private accountancy professionals to handle the consequential change management capacity which will be required to meet service delivery aims for e-government. 
It will be useful for the Revenue to investigate any barriers and constraints that are hindering progress towards meeting its above service delivery targets and how the department is dealing with them in order to minimise the risks of not achieving their e-taxation strategy. Such risks might be classified as internal (e.g. organisational capabilities) or external (e.g. reliance on outcomes from partnership working) and weighted according to their degree of impact and probability. Any assessment of these risks will go a long way in achieving the Government's goal of delivering a fully-automated e-taxation service in the UK.

\section{References}

[1] Grant, G., Realising the promise of electronic government, Journal of Global Information Management 13(1): i-iv, 2005.

[2] Heeks, R., Most egovernment-for-development projects fail: How can risks be reduced? http://idpm.man.ac.uk/publications/wp/igov/index.shtml, 2003.

[3] Norris, P., Deepening democracy via e-governance, draft chapter for UN world public sector report.

[4] http://ksghome.harvard.edu/ pnorris/ACROBAT/e-governance.pdf, 2005.

[5] OECD, The e-government imperative. OECD e-government studies. http://www1.oecd.org/publications/e-book/4203071E.PDF, 2003.

[6] Seifert, J. W. \& Bonham, G. M., The transformative potential of egovernment in transitional democracies. http://www.maxwell.syr.edu/maxpages/faculty/gmbonham/Transformative Potential of E-Government.pdf, 2003. 